\title{
Betung bamboo-based activated carbon bioadsorbent for the separation of hydrogen-methane gas mixture
}

\author{
Mahmud Sudibandriyo ${ }^{1 *}$, Melody Oratmangun ${ }^{1}$ \\ ${ }^{1}$ Department of Chemical Engineering, Universitas Indonesia, Depok, Indonesia
}

\begin{abstract}
Hydrogen recovery from off gas of hydrocracking and hydrotreating unit is one of the crucial processes in an oil and gas refinery unit as this process helps in lowering the expenses for operations. This study aims to obtain activated carbon that is made from Betung bamboo which can be used as the adsorbent in this process. The activated agents used are $\mathrm{H}_{3} \mathrm{PO}_{4}$ and $\mathrm{K}_{2} \mathrm{CO}_{3}$, respectively. Each activation lasts for 30 minutes. The results of the characterization test shows that the Iodine number of the activated carbon produced reaches $916.4 \mathrm{mg} / \mathrm{g}$ with BET surface area of $465.2 \mathrm{~m}^{2} / \mathrm{g}$. SEM-EDX analysis shows that the carbon content is $74.83 \%$. The activated carbon obtained is used to separate Hydrogen and Methane from its mixture at 10 , 20 and $30^{\circ} \mathrm{C}$ with pressure variations of $1-6$ bar. The results indicate that the maximum number of moles adsorbed from $\mathrm{CH}_{4}(21.5 \%) / \mathrm{H}_{2}$ gas mixture is $0.247 \mathrm{mmol} / \mathrm{g}$, that has been carried out at 6 bar with temperature of $10^{\circ} \mathrm{C}$. Methane has 2.2 times higher adsorption capacity than hydrogen, therefore, the Betung bamboo based activated carbon produced from this research can be applied as the adsorbent in the separation process of $\mathrm{CH}_{4} / \mathrm{H}_{2}$ mixture and it fits the Langmuir model.
\end{abstract}

\section{Introduction}

The recent downturn situation of the oil and gas industry has created a threat for companies in terms of making operational expenses. One of the prominent ways to help solve this problem is by applying the Pressure Swing Adsorption (PSA) Technology to recover hydrogen from the off gas of hydrocracking and hydrotreating processes. The PSA technology is said to be more economical than other technologies as it costs $\$ 1.29 / \mathrm{kg}$ hydrogen gas recovered [1]. A potential adsorbent that is used for this technology is the activated carbon.

The commercial activated carbon is mainly manufactured from coal. However, as the world is shifting to maximize the utilization of renewable energy resources, researchers have found several agricultural products that are feasible to be the raw materials of activated carbon. One of them is Betung bamboo (Dendrocalamus asper). Betung bamboo is an organic material which contains high amount of carbon. Therefore, previous researches have claimed that this material can be used as the raw material for activated carbon [2]. Moreover, it also contains high amount of cellulose, lignin, pentosan, ash and silica. Compared to other types of bamboo, Betung bamboo (Dendrocalamus asper) is said to contain more Lignin and Cellulose as much as $52.9 \%$ and $24.8 \%$, respectively [3]. There are two activating agents used in this study, which are phosphoric acid and potassium carbonate [2]. By doing two times chemical activation with two different activating agents, the result of the activated carbon obtained might have better characterization.
Therefore, this study aims to obtain activated carbon which can be used to recover hydrogen from hydrogenmethane gas mixture. Previous research done by Putri and Sudibandriyo shows that palm shell based activated carbon can be utilized to separate hydrogen from $\mathrm{CH}_{4}(1.5 \%) / \mathrm{H}_{2}$ and $\mathrm{CH}_{4}(8.5 \%) / \mathrm{H}_{2}$ by isothermal adsorption at 10,20 and $30^{\circ} \mathrm{C}$ [4]. Thus, in this research, the composition of the $\mathrm{CH}_{4}$ in the gas mixture is risen up to $21.5 \%$. This study is also carried out at $\mathrm{CH}_{4}(1.5 \%) / \mathrm{H}_{2}$ at $20^{\circ} \mathrm{C}$ to compare the adsorption performance of the activated carbon from bamboo and the one from palm shell from the previous study.

\section{Methodology/Experimental}

This study consists of two parts, such as the preparation of the activated carbon and the adsorption test. The performance of the activated carbon obtained is tested on the adsorption of pure hydrogen and methane gas at $20^{\circ} \mathrm{C}$, and then it is also tested to separate the gas mixture of hydrogen and methane at 10,20 and $30^{\circ} \mathrm{C}$ with pressure variation of $1-6$ bar. The results of this study will be compared to Putri and Sudibandriyo [4] results which utilized Palm Shell as the raw material of the activated carbon that will be used in the gas separation process.

\subsection{Adsorbent Preparation}

Firstly, the bamboo size is reduced to $1-2 \mathrm{~mm}$ before being soaked in aquadest to wash away any dirt. It is then dried in the oven at $100^{\circ} \mathrm{C}$ for 3 hours, until the weight is

* Corresponding author: msudib@che.ui.ac.id 
constant. After the drying process, it undergoes the first chemical activation using phosphoric acid $\left(\mathrm{H}_{3} \mathrm{PO}_{4}\right) 40 \%$ with mass ratio of $3: 1$ (mass of $\mathrm{H}_{3} \mathrm{PO}_{4}$ : mass of bamboo). This ratio is chosen based on the result of the previous experiment done by Wang, et al [2]. The mixture of bamboo and phosphoric acid is then dried in the oven for 12 hours at $80^{\circ} \mathrm{C}$. The chemical activation continues in a batch reactor at $450^{\circ} \mathrm{C}$ for half an hour. During this process, $40 \mathrm{~cm}^{3} / \mathrm{min} \mathrm{N}_{2}$ flows through the reactor continuously which result in an inert environment in the reactor. To neutralize the $\mathrm{pH}$ of the activated carbon obtained from the first chemical activation, sodium hydroxide $(\mathrm{NaOH}) 0.1 \mathrm{~N}$ is used [4]. Then it is dried again at $100^{\circ} \mathrm{C}$ for 2 hours. The second chemical activation uses potassium carbonate $\left(\mathrm{K}_{2} \mathrm{CO}_{3}\right) 20 \%$ as the activating agent in the ratio of $3: 1$ to the mass of activated carbon obtained from the first activation. The mixture is then dried at $50^{\circ} \mathrm{C}$ for 12 hours. The dried mixture will undergo the activation process in the reactor with $40 \mathrm{~cm}^{3} / \mathrm{min} \mathrm{N}_{2}$ flow. The second activation lasts for half an hour at $750^{\circ} \mathrm{C}$. The activated carbon obtained is washed by acetic acid $\left(\mathrm{CH}_{3} \mathrm{COOH}\right) 0.1 \mathrm{~N}$ to again neutralize the $\mathrm{pH}$. It is then washed again by aquadest to remove any molecules of the activating agent and other dirt which may cover up the pores. The final drying process of the activated carbon lasts for 2 and a half hours at $110^{\circ} \mathrm{C}$.

\subsection{Adsorbent Characterization}

The activated carbon that is obtained from Betung bamboo is characterized using several analysis, such as BET analysis, SEM-EDX analysis and Iodine number. BET surface area analysis is used to determine the surface area of the activated carbon using 0.3 gram sample. SEMEDX analysis shows the morphology of the activated carbon obtained and also the composition of each component present in the sample. Iodine number indicates the activated carbon ability to adsorbed iodine per gram of sample. To obtain the iodine number, 0.1 gram of activated carbon is stirred and heated with $10 \mathrm{ml}$ of iodine solution for 1 hour. It is then titrated by $\mathrm{Na}_{2} \mathrm{SO}_{3}$. The numbers obtained from the titration method are calculated to obtain the iodine number of this activated carbon.

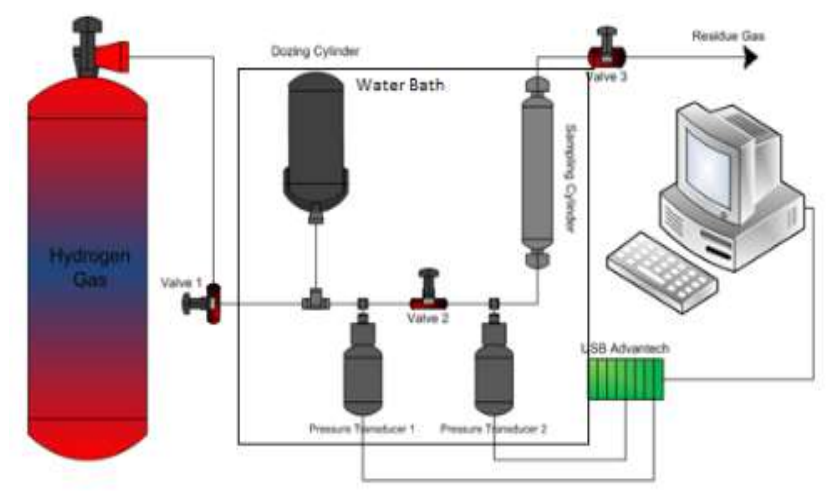

Fig. 1. Schematic Diagram of the Adsorption Test Apparatus [2]

\subsection{Adsorption Test}

The experimental apparatus used for the adsorption test is shown schematically in Fig. 1. As shown, it consists of the gas cylinder, dozing cylinder, sampling cylinder, pressure transducers, valves and monitor.

The sampling cylinder should be filled with the activated carbon. The void volume, $\mathrm{V}_{\text {void, }}$ of the sampling cylinder can be determined using the apparatus and helium gas. Helium gas is chosen as it is an inert gas. The data needed to calculate the void volume can be determined by opening valve 1 to inject known amount of helium gas to the dozing cylinder. While doing this, valve 2 should be closed to prevent gas flowing to the sampling cylinder. After the dozing cylinder is fully filled, valve 2 is open until it reaches the desired pressure $(1-6$ bar $)$. During this process, valve 1 and 3 must be closed. When this method has been applied to all pressure variations of $1-6$ bar, the calculation of the void volume is done using the following equation.

$$
V_{\text {void }}=\frac{n_{i} z_{H e, S C} R T_{S C}}{P_{S C}}
$$

The amount of the helium that is injected to the sampling cylinder, $\mathrm{n}_{\mathrm{i}}$, is calculated by

$$
n_{i=}\left[\left(\frac{P_{i}}{Z_{H e, i} R T_{i}}-\frac{P_{f}}{Z_{H e, f} R T_{f}}\right) V_{D C}\right]
$$

Where $\mathrm{V}_{\mathrm{DC}}$ represents the volume of the dozing cylinder, $P_{i}$ and $P_{f}$ are the initial and final pressure of the dozing cylinder and $Z_{\mathrm{He}}$ is the compressibility factor of helium gas injected at different pressure. The void volume that is used for further calculation is the average of void volume obtained at each pressure. The deviation standard should also be calculated to know the validity of this void volume calculation. The adsorption test is carried out with similar method. Both type of gas, pure and mixture, is injected to the dozing cylinder. Equation 2 is used in order to know the amount of gas injected, $\mathrm{n}_{\mathrm{i}}$. During this separation process, some amount of the injected gas will be adsorbed and some will still be presence in the equilibrium bulk phase, known as $\mathrm{n}_{\text {unads. }}$. It can be calculated by the following equation

$$
n_{\text {unads }}=\left(\frac{P V_{\text {void }}}{Z_{\text {gas }} R T}\right)_{\text {cell }}
$$

The equilibrium will be reached 30 minutes after the gas is injected from the dozing to the sampling cylinder. The stable pressure read on the pressure transducer indicates that it has reached equilibrium. The number of gas adsorbed, $\mathrm{n}_{\mathrm{ads}}$, is expressed as follow

$$
n_{\text {ads }}=n_{\text {inj }}-n_{\text {unads }}
$$

The equation should be modified to calculate the amount of gas adsorbed from the gas mixture in which the mole fraction of the injected and unadsorbed gas should be taken into account as seen below 


$$
n_{\text {ads }}=n_{\text {inj }} y_{i, i n j}-n_{\text {unads }} y_{i, \text { unads }}
$$

\subsection{Modeling}

The gas adsorption data are represented in using Langmuir isotherm adsorption model. There are several constants which should be determined in order to find the $\%$ AAD (Absolute Average Deviation). \%AAD indicates the error of the experimental data. As \%AAD matches the Gibbs adsorption model, $\mathrm{n}_{\text {adsmodel, }}$, with the experimental data, the $n_{\text {adsmodel }}$ that is expressed in the following equation

$$
n_{a d s}^{a b s}=n_{\max } \frac{b P}{1+b P}
$$

where $b$ is Langmuir constant, $n_{\max }$ is the maximum adsorption capacity and $P$ is the pressure in the sampling cylinder. This equation is solved by first guessing the value of $b$ and $n_{\max }$, The goal is to find the lowest number of $\% \mathrm{AAD}$ with the highest number of $n_{\max } \% \mathrm{AAD}$ is calculated based on equation 7 as shown below

$$
\% \mathrm{AAD}=\frac{\sum_{i}^{N}\left|\frac{n_{\mathrm{exp}}-n_{\text {model }}}{n_{\exp }}\right| x 100}{N}
$$

Equation(1) - Equation(7) have been referred to [5].

\section{Result and Discussion}

In this section, the result of the activated carbon obtained and its performance to adsorb pure methane, pure hydrogen and the mixture of both gas will be discussed further. Moreover, the Langmuir parameters calculation will also be discussed further to determine how well the experimental data fits the Langmuir isothermal model.

\subsection{Adsorbent Preparation and Characterization}

Both chemical activation in the reactor (using $\mathrm{H}_{3} \mathrm{PO}_{4}$ and $\mathrm{K}_{2} \mathrm{CO}_{3}$ ) show $23 \%$ loss in the mass of the activated carbon. It is calculated by subtracting final mass of activated carbon obtained from the initial mass that is before being activated in the reactor. The weight loss in the reactor is caused by the loss of water content present in the sample and the development of pores.

There are two activating agents used in this experiment in order to obtain activated carbon with higher surface area and better performance in adsorption. $\mathrm{H}_{3} \mathrm{PO}_{4}$ creates phosphate bonds/crosslinks that connects the carbon layers. It also clears off any tar and other dirt formation. $\mathrm{H}_{3} \mathrm{PO}_{4}$ is used rather than $\mathrm{KOH}$ as when used at the same temperature, this acidic solution will result in activated carbon with higher adsorption performance [2]. Moreover, the use of $\mathrm{H}_{3} \mathrm{PO}_{4}$ requires lower activation temperature, thus produce lower amount of pollutant [4]. As stated by Lillo-Rodenas et al. (2004), the hydroxyl group present in $\mathrm{KOH}$ is dangerous and corrosive. Therefore, it is not recommended to be used in the making of High Surface Area Activated Carbons (HSAAC) [6].
Therefore, the second activating agent used in this experiment is $\mathrm{K}_{2} \mathrm{CO}_{3}$.

This activated carbon has the BET surface area of $465.2 \mathrm{~m}^{2} / \mathrm{g}$. This surface area is slightly higher compared to previous research by [3] in which the activated carbon obtained from palm shell have the BET surface area of $414.91 \mathrm{~m}^{2} / \mathrm{g}$. The BET surface area obtained in this research is higher than the previous work which utilizes bamboo as the raw material for activated carbon by doing chemical activation with $\mathrm{Na}_{2} \mathrm{CO}_{3}$. The surface area of the activated carbon obtained is $74.5 \mathrm{~m}^{2} / \mathrm{g}$. The higher surface area of the activated carbon obtained from this research is due to the two times activation that have been undergone. The Iodine number of the activated carbon produced is $916.4 \mathrm{mg} / \mathrm{g}$. This number is still acceptable as the requirement for the iodine number of activated carbon is $200 \mathrm{mg} / \mathrm{g}$, based on the Indonesian National Standard.

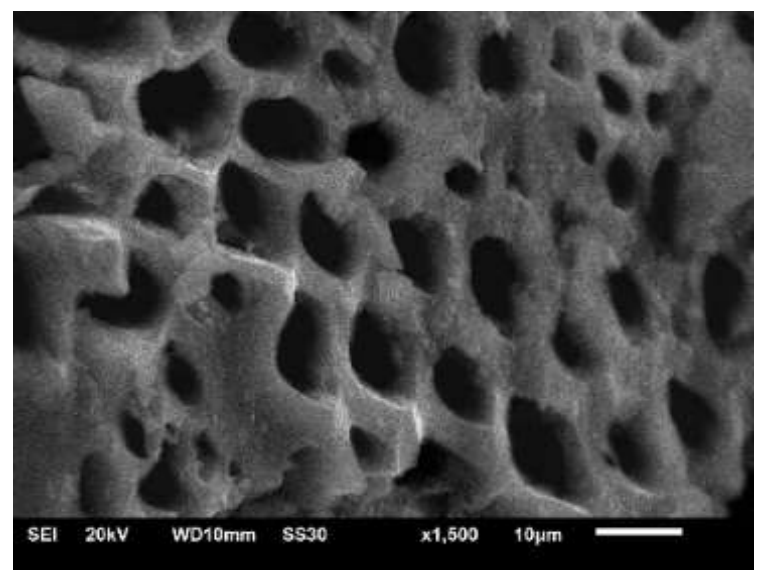

Fig. 2. SEM-EDX Result (1500x)

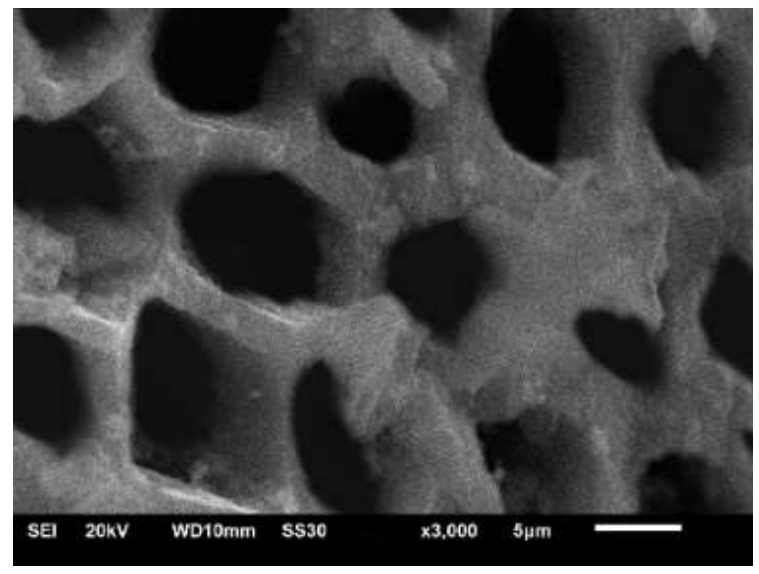

Fig. 3. SEM-EDX Result (3000x)

From SEM-EDX analysis, the composition of each element present in the activated carbon can be determined. The activated carbon is dominated by carbon component which reaches $74.83 \%$. This number exceeds the Indonesian National Standard which states that the minimum Carbon content in an activated carbon is $65 \%$. Other elements that are present in the activated carbon are Oxygen, Aluminium, Zinc, etc. Those elements might come from the apparatus used and also the solution that is used to wash or neutralize the activated carbon. 
Fig. 2 and Fig. 3 show the morphology of the activated carbon in 1500x and 3000x magnification, respectively. From the result seen on the figures below, the activated carbon obtained is porous, although there are still several dirty molecules covering up the pores. More amount of aquadest would be needed to clear off the dirt. However, in comparison to other activated carbon from bamboo works, the SEM-EDX result from this experiment has shown that the material produced from this experiment can be morphologically classified as an activated carbon.

\subsection{Adsorption Test and Modeling}

The void volume of the activated carbon in the sampling cylinder calculated is $3 \mathrm{ml}$. It is the average of six trials that have been carried out at $1-6$ bar.

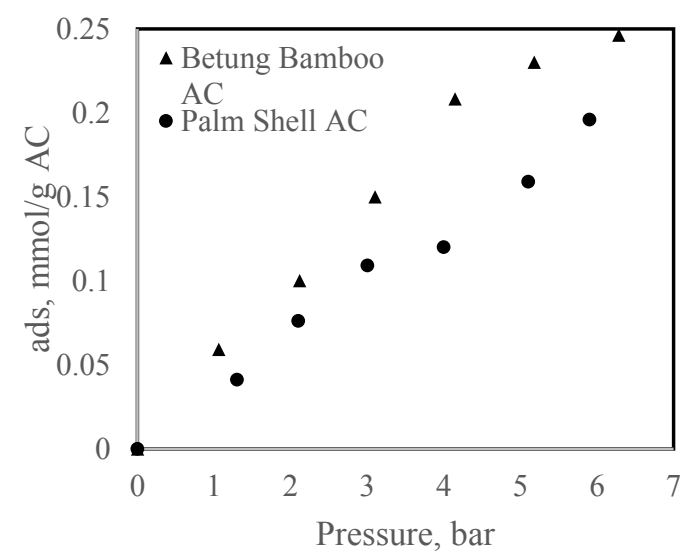

Fig. 4. Adsorption of $\mathrm{CH}_{4}(1.5 \%) / \mathrm{H}_{2}$ at $20^{\circ} \mathrm{C}$ on Palm Shell and Betung Bamboo Activated Carbon

Table 1. Performance Comparison of Betung Bamboo and Palm Shell Based Activated Carbon

\begin{tabular}{|c|c|c|}
\hline \multirow{4}{*}{ Raw Material } & Pressure (bar) & $\begin{array}{c}\text { Adsorption } \\
\text { (mmol/g AC) }\end{array}$ \\
\hline \multirow{4}{*}{ Betung Bamboo } & 1.06 & 0.059 \\
\cline { 2 - 3 } & 2.06 & 0.100 \\
\cline { 2 - 3 } & 3.08 & 0.150 \\
\cline { 2 - 3 } & 4.16 & 0.208 \\
\cline { 2 - 3 } & 5.09 & 0.230 \\
\hline \multirow{4}{*}{ Palm Shell } & 6.12 & 0.246 \\
\cline { 2 - 3 } & 1.30 & 0.041 \\
\cline { 2 - 3 } & 2.10 & 0.076 \\
\cline { 2 - 3 } & 3.00 & 0.109 \\
\cline { 2 - 3 } & 4.00 & 0.120 \\
\cline { 2 - 3 } & 5.10 & 0.159 \\
\hline
\end{tabular}

Fig. 4. and Table 1 show the performance comparison of the activated carbon obtained from bamboo and the one from palm shell from the previous research carried out by Putri and Sudibandriyo [4]. It is shown that the activated carbon obtained from this research adsorps more molecules than the one from palm shell does. It might be caused by the higher surface area that the activated carbon from bamboo has. Tabel 2 and Fig. 5. show the result of the isothermal adsorption of $\mathrm{CH}_{4}(99.9 \%), \mathrm{H}_{2}(99.9 \%)$ and $\mathrm{CH}_{4} / \mathrm{H}_{2}$ with $21.5 \% \mathrm{CH}_{4}$. It is shown that the highest adsorption belongs to pure $\mathrm{CH}_{4}$ which reaches 0.290 $\mathrm{mmol} / \mathrm{g}$, followed by the mixture of $\mathrm{CH}_{4} / \mathrm{H}_{2}$ as much as $0.203 \mathrm{mmol} / \mathrm{g}$ and lastly pure $\mathrm{H}_{2}$ with the value of 0.131 $\mathrm{mmol} / \mathrm{g}$.

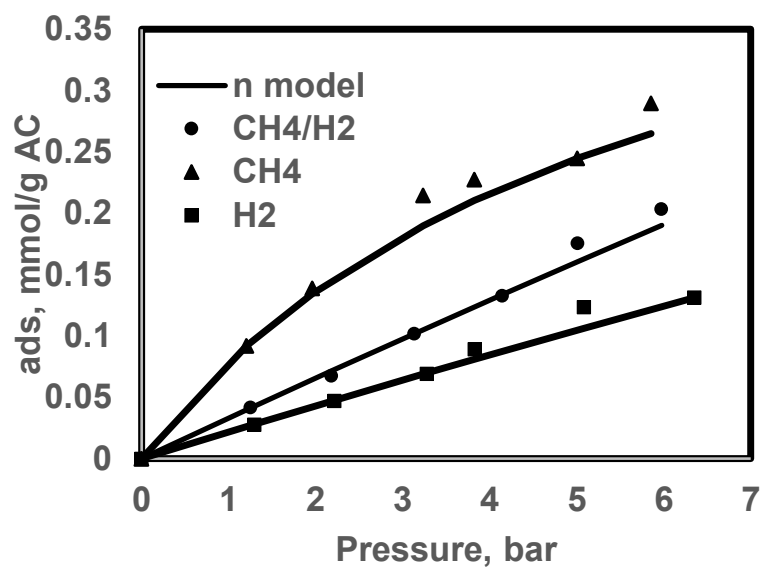

Fig. 5. Adsorption of $\mathrm{CH}_{4}, \mathrm{H}_{2}$ and $\mathrm{CH}_{4}(21.5 \%) / \mathrm{H}_{2}$ at $20^{\circ} \mathrm{C}$

Table 2 shows the result of adsorption at $20^{\circ} \mathrm{C}$ with different gas composition.

Table 2. Adsorption Result of $\mathrm{CH}_{4}, \mathrm{H}_{2}$ and $\mathrm{CH}_{4}(21.5 \%) / \mathrm{H}_{2}$ at $20^{\circ} \mathrm{C}$

\begin{tabular}{|c|c|c|}
\hline Adsorbate & Pressure (bar) & $\begin{array}{c}\text { Adsorption } \\
\text { (mmol/g AC) }\end{array}$ \\
\hline \multirow{6}{*}{$\mathrm{CH}_{4}$} & 1.21 & 0.092 \\
\hline & 1.96 & 0.139 \\
\hline & 3.23 & 0.214 \\
\hline & 3.83 & 0.227 \\
\hline & 5.00 & 0.245 \\
\hline & 5.85 & 0.290 \\
\hline \multirow{6}{*}{$\mathrm{H}_{2}$} & 1.29 & 0.013 \\
\hline & 2.22 & 0.067 \\
\hline & 3.28 & 0.094 \\
\hline & 3.83 & 0.111 \\
\hline & 5.09 & 0.123 \\
\hline & 6.36 & 0.132 \\
\hline \multirow{6}{*}{$\mathrm{CH}_{4}(21.5 \%) / \mathrm{H}_{2}$} & 1.25 & 0.041 \\
\hline & 2.18 & 0.067 \\
\hline & 3.13 & 0.102 \\
\hline & 4.15 & 0.133 \\
\hline & 5.01 & 0.176 \\
\hline & 5.98 & 0.203 \\
\hline
\end{tabular}

The difference in the number of molecules adsorbed from each kind of gas is due to its molecular size. The molecular diameter of $\mathrm{CH}_{4}$ is $3.8 \mathrm{~A}$ and $2.8 \mathrm{~A}$ for $\mathrm{H}_{2}$. The average pores' diameter of activated carbon is around 16A. Therefore, only small amount of hydrogen molecules are adsorbed to the pores as they tend to stay in a bulk phase [4]. As the number of methane molecules 
adsorbed is higher than hydrogen molecules, it causes the gas mixture of $\mathrm{CH}_{4} / \mathrm{H}_{2}$ to have more molecules adsorbed compared to the number of pure hydrogen molecules adsorbed by the activated carbon. The results also indicate that the produced activated carbon has a high potential to be used to separate hydrogen from the hydrogen/methane gas mixtures.

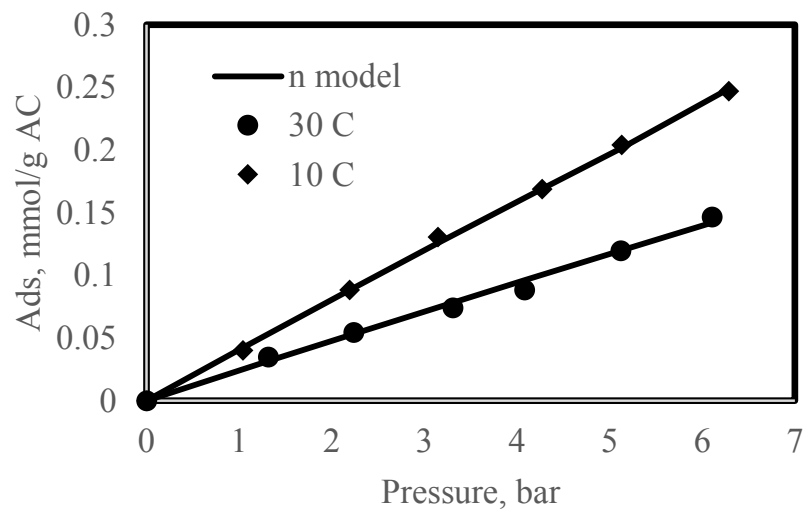

Fig. 6. Adsorption of $\mathrm{CH}_{4}(21.5 \%) / \mathrm{H}_{2}$ at $10^{\circ} \mathrm{C}$ and $30^{\circ} \mathrm{C}$

Table 3. Adsorption Results of $\mathrm{CH}_{4}(21.5 \%) / \mathrm{H}_{2}$ at $10{ }^{\circ} \mathrm{C}$ and $30^{\circ} \mathrm{C}$

\begin{tabular}{|c|c|c|}
\hline Temperature $\left({ }^{\circ} \mathrm{C}\right)$ & $\begin{array}{c}\text { Pressure } \\
\text { (bar) }\end{array}$ & $\begin{array}{c}\text { Adsorption } \\
\text { (mmol/g AC) }\end{array}$ \\
\hline \multirow{6}{*}{10} & 1.04 & 0.041 \\
\hline & 2.19 & 0.089 \\
\hline & 3.14 & 0.131 \\
\hline & 4.27 & 0.169 \\
\hline & 5.13 & 0.204 \\
\hline & 6.29 & 0.247 \\
\hline \multirow{6}{*}{30} & 1.32 & 0.035 \\
\hline & 2.24 & 0.055 \\
\hline & 3.31 & 0.074 \\
\hline & 4.08 & 0.088 \\
\hline & 5.12 & 0.120 \\
\hline & 6.10 & 0.145 \\
\hline
\end{tabular}

Tabel 3 and Fig. 6. shows the result of $\mathrm{CH}_{4}(21.5 \%) / \mathrm{H}_{2}$ adsorption on activated carbon at isothermal condition of 10 and $30^{\circ} \mathrm{C}$. The graphs obtained indicate that the amount of gas molecules adsorbed increases along with the increase in pressure. The result also shows that at lower temperature, the amount of gas adsorbed is higher than at the higher one. Based on Le Chatelier principle, exothermic reaction would favour lower temperature. Thus, as adsorption is classified as exothermic, the adsorption result should be higher at lower temperature.

The results obtained from this experiment are fitted to the Langmuir isotherm model as shown on Fig 5. and Fig. 6 . This model represents the physical interaction between the adsorbate and adsorbent molecules [5]. The data obtained from the experiment results in a low \%AAD (below 10\%) which means that the experimental data are representative and valid. The $b$ constant in the Langmuir model describes the strength of gas molecules being adsorbed to the surface of the activated carbon. This $b$ parameter is described as follow

$$
b=\left(\frac{\propto}{k_{d \infty} \sqrt{2 \pi m k T}}\right) \exp \left(\frac{Q}{R T}\right)
$$

Table 4 and Table 5 show the result of Langmuir parameter of each variation.

Table 4. Langmuir Parameters of Methane and Hydrogen Isothermal Adsorption

\begin{tabular}{|c|c|c|c|}
\hline Adsorbate & $\boldsymbol{n}_{\max }$ & $\boldsymbol{b} \mathbf{x} \mathbf{1 0}^{\mathbf{2}}$ & \%AAD \\
\hline $\mathrm{CH}_{4}$ & 1.314 & 1.90 & 1.18 \\
\hline $\mathrm{H}_{2}$ & 1.132 & 2.00 & 5.48 \\
\hline
\end{tabular}

Table 5. Langmuir Parameters of $\mathrm{CH}_{4}(21.5 \%) / \mathrm{H}_{2}$ Adsorption at 10,20 and $30^{\circ} \mathrm{C}$

\begin{tabular}{|c|c|c|c|}
\hline Temperature $\left({ }^{\circ} \mathbf{C}\right)$ & $\boldsymbol{n}_{\max }$ & $\boldsymbol{b} \mathbf{x 1 0}$ & \%AAD \\
\hline 10 & 4.70 & 8.75 & 1.97 \\
\hline 20 & 4.41 & 7.53 & 3.68 \\
\hline 30 & 4.29 & 5.62 & 4.97 \\
\hline
\end{tabular}

$b$ increases with a decrease in temperature, as seen on Equation 8. $n_{\max }$ also varies unproportionally with temperature as it correlates with the surface area of the adsorbent and the surface density of the adsrobate. Surface density of an adsorbate is found to be higher at lower temperature [7]. In accordance to Yuliusman et al research, activated carbon has the highest adsorption capacity compared to other types of adsorbent when fitted to Langmuir isotherm model. [8]

\section{Conclusion}

Activated carbon obtained from from Betung bamboo has the BET surface area of $465.2 \mathrm{~m}^{2} / \mathrm{g}$ with iodine number of $916.4 \mathrm{mg} / \mathrm{g}$. The adsorption result shows that the highest Gibbs adsorption capacity is achieved by methane, followed by $\mathrm{CH}_{4} / \mathrm{H}_{2}$ mixture and lastly, pure $\mathrm{H}_{2}$. Methane has 2.2 times higher adsorption capacity than hydrogen, therefore, the Betung bamboo based activated carbon produced from this research can be applied as the adsorbent in the separation process of $\mathrm{CH}_{4} / \mathrm{H}_{2}$ mixture.

The author would like to thank all parties that have supported this study, especially Universitas Indonesia via Grant of International Publication Indexed for Thesis of UI's Students or known as PITTA 2018 (Grant no. 2473/UN2.R3.1/HKP.05.00/2018).

\section{References}

1. A. Mivechian, M. Pakizeh., Korean Journal of Chemical Engineering 30(4), 937-948 (2013)

2. Y. Wang, H. Ngo, W. Guo, Sci. Preparation of a Specific Bamboo Based Activated Carbon and its 
Application for Ciprofloxacin Removal, Sci. Total Environ., 533, 32-39 (2015)

3. G, Gusmailina, S. Suwardi. Analisis Kimia Sepuluh Jenis Bambu dari Jawa Timur. Journal of Forest Product Research, 5(5), E-ISSN 2442-8957 (1988)

4. S. N. Putri, M. Sudibandriyo, Hydrogen Recovery from Hydrogen-Methane Gas Mixture Utilized by Palm Shell Bioadsorbent Activated Carbon, Proceeding of the $15^{\text {th }}$ International Conference on QIR, ISSN 1411-1284, (2017)

5. M. Sudibandriyo, IJET, 11, $79-82$ (2011)

6. M. Lillo-Rodenas, D. Cazrola-Amoros, A. LinaresSolano, F. Beguin, C. Clinard. J. Rouzaud. Carbon, 42(7), 1305 - 1310 (2004)

7. M. Sudibandriyo, Z. Pan, J. Fitzgerald, R. Robinson, K. Gasem, Langmuir, 19(13), 5323 - 5331 (2003)

8. Yuliusman,W.W. Purwanto, Y.S. Nugroho, IJTech, 3, $492-503(2015)$ 